\title{
Standing Out and Sorting In: Exploring the Role of Racial Composition in Racial Disparities in Special Education
}

\author{
Rachel Elizabeth Fish \\ New York University
}

Schools differentially sort students into special education by race, though researchers debate the extent to which this is caused by racist school practices versus variation in student need due to other racial inequalities. I test the interaction between school-level racial composition and student-level race as a predictor of special education receipt. I find that as the proportion of White students increases, the risk of lower-status disabilities, such as intellectual disability, increases for Black, Latinx, and Native American students. As the proportion of White students decreases, White students' risk of higherstatus disabilities, such as speech/language impairment, increases relative to students of color. Thus, in the context of racial distinctiveness, student race becomes salient to sorting into special education.

KEYwORDS: race, special education, disability, racial composition

T he disproportionate rates of special education receipt by students from low-income and racial minority backgrounds in the United States has been documented since at least the late 1960s (Dunn, 1968; Mercer, 1973). Moreover, racial disparities vary between the 13 federally defined educational disabilities, with some of the greatest disproportionality occurring in emotional disturbance and intellectual disability (U.S. Department of Education, Office of Special Education and Rehabilitative Services, \& Office of Special Education Programs, 2015); relative to other categories of disability, these categories are associated with greater social stigma and

Rachel Elizabeth Fish is an assistant professor in the Department of Teaching and Learning at New York University, 239 Greene Street, 6th Floor, New York, NY 10003, e-mail: rachel.fish@nyu.edu. She is also an affiliated faculty member in Sociology of Education and in the Metropolitan Center for Research on Equity and the Transformation of Schools at NYU. Dr. Fish is a sociologist of education. She studies how schools exacerbate and ameliorate inequality by race, gender, socioeconomic status, and linguistic background, focusing on sorting processes such as special and gifted education. 
higher rates of segregation from peers without disabilities (Blanchett, 2010; U.S. Department of Education, Office of Special Education and Rehabilitative Services, \& Office of Special Education Programs, 2015). Education policy, the U.S. justice system, and a large body of research treat the "overrepresentation" of students of color in special education as likely evidence of bias and inappropriate identification of students of color (Donovan \& Cross, 2002; Losen \& Welner, 2001; Oswald, Coutinho, Best, \& Nguyen, 2001; Skiba, Poloni-Staudinger, Simmons, Feggins-Azziz, \& Choong-Geun, 2005). Yet some new research challenges previous conclusions of racial bias by examining the relation between race and disability in light of confounders (e.g., socioeconomic status) and by better accounting for the nested nature of students within school contexts (Hibel, Farkas, \& Morgan, 2010; MacMillan \& Reschly, 1998; Morgan et al., 2015; Shifrer, 2018; Shifrer, Muller, \& Callahan, 2011). This research suggests that students of color are not overrepresented at all, but rather they may actually be underrepresented in special education once confounders are taken into account (Hibel et al., 2010; Morgan et al., 2015). However, other research suggests that the relation between race and risk of special education receipt depends on the disability category, as children of color have greater risk than White children when they exhibit behavioral challenges, and White children have greater risk than children of color when they exhibit academic challenges (Fish, 2017).

A growing body of research examines the role of school context in the production or reduction of racial inequalities in special education, focusing on racial composition as a potential explanation for racial disparities in special education receipt (Bal, Betters-Bubon, \& Fish, 2017; Eitle, 2002; Hibel et al., 2010; Sullivan \& Bal, 2013). Most of this research has treated school racial composition as a potential confounder of race effects-one that would have universal effects on all students' risk of special education. Yet it is likely that the racial context of the school, which has been shown to shape withinschool racial inequalities such as sorting into tracks (e.g., Lucas \& Berends, 2002), might have different effects on risk of special education receipt by race.

Understanding the nature of the relationship between race and educational disability has important implications beyond the question of whether schools are inappropriately placing children in special education due to racially biased practices (Skiba et al., 2005) or whether they are merely responding to broader racial inequalities that increase the need for special services among children of color (Shifrer et al., 2011). This empirical question is certainly important for understanding racial disparities among students with educational disabilities, who make up 13\% of public school students and are largely served in general education classrooms (National Center for Education Statistics, 2017; U.S. Department of Education, Office of Special Education and Rehabilitative Services, \& Office of Special Education Programs, 2015). Yet this question also has the potential to 
contribute to theoretical understanding of the often-neglected intersection of race and disability (Erevelles \& Minear, 2010). Examining racial disparities in special education receipt provides a window into one mechanism of "categorical inequality" (Domina, Penner, \& Penner, 2017), in which schools sort children into different categories of disability and into different services. This sorting likely allocates many beneficial resources to students that need them most. However, it may also exacerbate racial inequalities by creating structures for opportunity hoarding, shaping incentives and student motivation, affecting identity formation, and creating lasting status distinctions (Domina et al., 2017), particularly for the medicalized categories of educational disabilities.

In this article, I expand on existing empirical studies of inequality in special education by testing the cross-level interaction between school-level racial composition and student-level race, predicting sorting into special education under different categories of educational disability. I use a large data set of all students in Wisconsin, allowing for the nuanced examination of variation across the more subjective, higher-incidence disability categories. The data set also allows for examination of racial differences including Native American students, who are often excluded from analyses due to sample constraints. I seek to reveal how race intersects with schools' construction of disability categories and to understand how schools sort into these categories.

\section{The Social Context of Disability}

Mainstream practitioners, policymakers, and scholars generally conceive of educational disabilities as individual-level neurophysiological pathologies with clear boundaries between categories of disability (Dudley-Marling, 2004; Reid \& Knight, 2006; Reid \& Valle, 2004). Yet this framing ignores the ways in which disability is also socially constructed (McDonald, Keys, \& Balcazar, 2007) and driven by institutional practice (Mehan, Hertweck, \& Meihls, 1986) and by the medicalization of underperformance (Conrad, 1976). Subjectivity infuses all steps of the special education placement process, from teacher referrals (Brinkman et al., 2009; Cormier, 2012; Lloyd, Kauffman, Landrum, \& Roe, 1991; Sax, 2003), to psycho-educational testing and interpretations of that testing (Mehan et al., 1986), to team meetings to determine eligibility (Harry \& Klingner, 2007). This subjectivity allows biases, preferences, politics, and other individual and contextual factors to shape which students are seen as having disabilities. Moreover, indicators of some disability categories partially overlap with one another, creating grey areas of qualification where social factors could affect the particular category that is diagnosed (Eyal, 2013; Liu, King, \& Bearman, 2010; Ong-Dean, 2009). For instance, both speech/language disorder and intellectual disability can be characterized by language-processing challenges; similarly, both autism 
spectrum disorder and emotional disturbance might be diagnosed due to social and behavioral challenges (Smith \& Tyler, 2015). As a result, team decisions of diagnosis are based not only on assessment tools but are also subject to the discretion of individuals, allowing social factors to affect these bureaucratic decisions (Lipsky, 1971).

An essentialist and medicalized framing also treats racial disparities in special education as mere variation in incidence, missing the intersectional relation between disability and race as categories that co-construct one another (Erevelles \& Minear, 2010). A focus on the social context of disability does not negate the real academic, behavioral, and social challenges experienced by students identified with disabilities. Rather, it casts a critical lens on the line dividing students diagnosed with disabilities from those with uncategorized, nonmedicalized low performance or social/behavioral challenges and allows for the examination of how individual and contextual factors might affect disability diagnosis.

A subset of educational disabilities is generally considered more subjective than "hard disabilities" (e.g., D/deafness, blindness, and orthopedic impairment): autism spectrum disorder, emotional disturbance, intellectual disability (including only mild intellectual disability, the majority of intellectual disability diagnoses; Garfunkel, Kaczorowski, \& Christy, 2007), other health impairment (includes a wide range of health needs that can affect learning but is most commonly for attention deficit/hyperactivity disorder [ADHD]; Grice, 2002), specific learning disability, and speech-language impairment (Connor, 2005; Donovan \& Cross, 2002). I focus on these categories as the subjectivity allows for greater influence of social factors on special education placement decisions, allowing for examination of school- and student-level variation in how students are sorted into special education.

\section{Social Status of Disability}

Special education is generally understood and treated as a social good, a civil right that students with disabilities were not guaranteed until 1975 (U.S. Department of Education \& Office of Special Education and Rehabilitative Services, 2010). Indeed, these services have expanded access and improved educational programming for children with disabilities. Yet disability identification and the provision of special education services may also reify a core axis of societal inequality by ability, as students experience stigma, isolation from peers, lower teacher expectations, and less access to higher-level content (Dudley-Marling, 2004; Gillung \& Rucker, 1977; Morgan, Frisco, Farkas, \& Hibel, 2010; Shifrer, Callahan, \& Muller,

2013). Cognitive and behavioral abilities, broadly defined, are valued to the extent that people with disabilities are seen as "pathological and incompetent," deserving exclusion from social life (McDonald et al., 2007). As 
a result, not having a disability generally affords a person higher social status than having a disability.

Status differences also exist between categories of disability (Thomas, 2000; Tringo, 1970). Delineating this social hierarchy is useful for understanding how schools sort students into disability categories. While scholars typically infer disability status differentiation from other social statuses (i.e., by race and socioeconomic status) of the populations that are more likely to be identified with them (Blanchett, 2010; Ong-Dean, 2006; Sleeter, 1987), I define disability statuses in terms of variation in stigma, the types of services provided, the extent of exclusion from the general education classroom, and parental preferences for particular disability diagnoses. The typology presented here is not based on the specific criteria for qualification, the presentation of the disabilities, or the assessment procedures used for each diagnosis. I define three disability categories as higher status: other health impairment, speech-language impairment, and autism spectrum disorder; two categories as lower status: emotional disturbance and intellectual disability; and one disability category as stratified status: specific learning disability.

\section{Higher-Status Disability Categories}

The three disabilities conceptualized as higher-status categories of disability are (1) other health impairment, which most frequently serves as the label for ADHD (Grice, 2002); (2) speech/language impairment, which refers to both speech impairments and language-processing deficits: and (3) autism spectrum disorder, which refers to social and communication impairments. These disabilities are associated with lower stigma among disability categories and more advantageous services than other categories (Blanchett, 2010; Harry \& Anderson, 1994; Ong-Dean, 2009), such as more inclusion in the general education classroom, which provides them with more access to grade-level content and social experiences with peers without disabilities (U.S. Department of Education, Office of Special Education and Rehabilitative Services, \& Office of Special Education Programs, 2015). For many presentations of these disabilities, these categories are defined and popularly perceived as having no relation to intelligence, or even having a positive relation to intelligence in contrast to other disabilities (Brown, 2011; Charman et al., 2011; Grandin, 2008). Research suggests that families with more resources may advocate for autism over intellectual disability and specific learning disability (Eyal, 2013; Liu et al., 2010; Ong-Dean, 2009), prefer ADHD (typically under the disability category of other health impairment) to mere "underperformance" (Conrad, 1976), and medicate ADHD strategically under academic pressure (King, Jennings, \& Fletcher, 2014). In the case of speech/language impairments, students are exited from special education at a relatively high rate (Special Education 
Longitudinal Study, 2005), suggesting a transitory need in contrast to the permanence of other categories.

\section{Lower-Status Disability Categories}

On the opposite end of the spectrum, two categories have lower status than the others: (1) emotional disturbance, a category defined by excessive problem behavior, and (2) intellectual disability, which refers to a deficit in the highly valued characteristic of intelligence, indicated by a combination of low IQ and challenges with adaptive behavior such as self-care. Both these categories are associated with greater social stigma than other disabilities (Blanchett, 2010; Harry \& Anderson, 1994; Ong-Dean, 2009), which has implications for how teachers, peers, and future employers will see the student. Emotional disturbance is associated with juvenile incarceration (Rutherford, Bullis, \& Anderson, 2002), and the label suggests that the child will likely disrupt teachers' classes. Intellectual disability is perceived as pathological incompetence and low status relative to other types of disability (McDonald et al., 2007; Thomas, 2000; Tringo, 1970). Students with these disabilities are excluded from the general education classroom at higher rates than their peers with other disabilities, reducing their access to grade-level content and isolating them from peers exhibiting low academic performance and/or problematic behaviors (U.S. Department of Education, Office of Special Education and Rehabilitative Services, \& Office of Special Education Programs, 2015).

\section{Stratified-Status Disability Category}

Specific learning disability refers to students who do not meet grade-level standards in one or more areas yet whose deficits are unexplained by any other disabilities or lack of appropriate instruction (Wisconsin Department of Public Instruction, n.d.). This disability confers higher status to some students and lower status to others (Blanchett, 2010; Ong-Dean, 2006); thus, I conceptualize it as a stratified-status disability. Specific learning disability rose in popularity as a way for more advantaged families to explain low performance (Blanchett, 2010; Ong-Dean, 2006; Sleeter, 1987) and is preferred by families over intellectual disability (Gottlieb \& Alter, 1994). Over time, incidence of specific learning disability has increased among students of color (Ong-Dean, 2006). Yet while the category has maintained higher status for students with more advantages-providing extra resources, a destigmatizing label, and the presumption of normal or superior intelligence-disadvantaged students likely receive few of those benefits (Blanchett, 2010; Ong-Dean, 2006). Rather the category may simply be a "dumping ground for children of color" who do not qualify for intellectual disability (Blanchett, 2010).

Presumably, parents, teachers, and children perceive "naturally" high achievement without disability as the most desired ability status. Yet among 
students who are struggling in school, it is arguably better to be labeled with a higher-status disability that provides accommodations, extra support from teachers, and a medicalized explanation for low performance (Conrad, 1976) than to be seen as nondisabled yet simply unmotivated or underperforming. The lower-status disability categories, then, are arguably the least desired among these possible categorizations of students, as they imply out-ofcontrol behavior or low intelligence and are most likely to exclude children from the general education classroom.

\section{Race, Racial Composition, and Sorting Into Special Education}

Among students exhibiting academic and social-behavioral challenges, how do schools sort students into categories of disability? Subjectivity in the process of identifying disabilities allows social factors, such as race and school racial composition, to affect referral, eligibility, the type of disability diagnosis, and placement into services. Existing research shows that racial bias and parental pressure affect teachers' decisions to refer students to special education testing, testing processes, and team decisions to qualify students for special education services (Fish, 2017; Harry \& Klingner, 2007). I argue that in addition to these individual-level factors, racial composition is likely to affect which students are identified with disabilities and thus receive special education services.

Decisions to place students in special education likely parallel other within-school sorting processes meant to specialize educational programming, such as tracks, ability groups, and gifted programs, in which racial composition moderates both the extent of tracking and racial disparities (Braddock, 1990; Lucas \& Berends, 2002; Mickelson, 2001; Oakes, 1985; Sleeter, 1987; Staiger, 2004). Research also suggests that racial composition moderates racial patterns of exclusionary disciplinary procedures (Edwards, 2016), in which students are sorted out of the classroom, and likely paralleling special education receipt for emotional disturbance (Bal et al., 2017). Existing research on racial disproportionality in special education that examines school context, however, generally examines universal effects of school racial composition. In other words, most of these studies assume that schools with different racial compositions may have different practices around special education but that these practices have the same effects on all students' risk of special education receipt regardless of race. This research has produced mixed findings on the effects of school racial composition (Bal et al., 2017; Hibel et al., 2010; Sullivan \& Bal, 2013).

Among studies on racial disproportionality in special education, only two (Eitle, 2002; Shifrer, 2018) go beyond universal effects of school racial composition, examining the relation between racial composition and racial disparities in special education receipt. Of these studies, only Shifrer's (2018) accounts for the hierarchical structure of the data of students nested 
in schools, and both these studies examine single disability categories. Shifrer's (2018) findings suggest a statistically nonsignificant interaction between school racial composition and student race, but the estimates are suggestive of higher risk of disability identification for students who are racially distinct in their schools. Eitle's (2002) findings support theories that special education facilitates within-school racial segregation in reaction to racial integration (Eitle, 2002; Ferri \& Connor, 2005; Mccall \& Skrtic, 2009). She suggests that racial composition may engender racial competition and political mobilization by parents, shaping who is identified with educational disabilities. Other plausible mechanisms include the possibility that school racial composition moderates the salience of racial stereotypes, which affect teachers' suspicions of disability (Fish, 2017), as well as the possibility that school racial composition might affect the social-psychological and academic well-being of students of color (Goldsmith, 2004; Hanselman, Bruch, Gamoran, \& Borman, 2014; Tyson, William Darity, \& Castellino, 2005), which, in turn, affect the need for special education services. The existing research leaves open many questions about what these patterns of race, composition, and special education are for a wider range of disability categories and how students are sorted into different categories of disability.

\section{Research Question}

In this article, I test the role of school racial composition as a moderator of the relation between race and special education receipt, examining variation by disability category. While previous research has largely examined student-level race and school-level racial composition as predictors of special education receipt, I test the cross-level interaction of school racial composition and student race. These analyses aim to reveal how schools sort students into these categories, shedding light on the role of special education in racial stratification, and the intersection of disability and race.

\section{Data and Measurement}

This research uses data from Wisconsin, a state with a wide range of racial compositions in its schools and notable racial inequalities in education, specifically special education (Vanneman, Hamilton, Anderson, \& Rahman, 2009). I use a data set from the Wisconsin Department of Instruction that includes all 895,791 students in all 2,214 schools in 20102011. Compared with the data used in previous research on contextual effects in racial disproportionality in special education, the focal data set has significant advantages, most important a very large population, rather than a representative sample. The sizeable numbers of students in individual disability categories allow for the estimation of categories excluded in some previous research. Because students in prekindergarten and Grades 2, 9, 11, 
and 12 do not receive scores through the Wisconsin Student Assessment System, I exclude these students from analyses that include individual achievement test scores; this adjustment results in a population of 429,488 students in 2,214 schools.

The dependent variables in this study are dichotomous variables of whether a student received special education services in the 2010-2011 school year $(0=$ did not receive services; $1=$ received services $)$, including an aggregate outcome of any disability as well as outcomes for each of the more subjective categories of disability discussed above (autism spectrum disorder, emotional disturbance, intellectual disability, other health impairment, specific learning disability, or speech/language impairment). The raw data showing the percentage of each racial group receiving services under each disability category are available in Table 1 . These data show that Black and Native American students are almost twice as likely as White students to receive special education services under any disability category. Black students outpace White students in receipt of special education under every category except for autism spectrum disorder, and Native American students also receive services at higher levels than White students across all categories. Latinx students' rates of receipt are less consistent across categories, while Asian students receive special education services at lower rates across all categories.

Descriptive statistics can be found in Table 2. The student-level independent variables of greatest interest are those for race, represented by dichotomous measures for all available racial categories in the data: Asian, Black, Latinx, Native American, and White $(0=$ White $)$. I include as individual-level controls all available measures that might confound the relation between race and special education receipt. English-language learner (ELL) status $(0=$ non-ELL $; 1=E L L)$ is associated with race and with both increased and decreased risk of special education receipt, as ELLs who struggle academically are more likely to receive English as a second-language programs -without special education services-when they are younger and more likely than their peers to receive special education when they are older (Hibel \& Jasper, 2012) and is included as a dichotomous variable. Socioeconomic status, discussed above as a potential confounder, is included via free/reduced-price lunch (FRL) status ( $0=$ non-FRL; $1=F R L)$. Risk of different disabilities varies by grade level (Shifrer \& Fish, 2015); thus, grade level is included, ranging from 3 to 10 in all models that use this variable, as these are the only grade levels in which students took academic proficiency tests. Gender is associated with special education receipt (Coutinho, Oswald, \& Best, 2002) and is included as a dichotomous measure $(0=$ female $; 1=$ male $)$. Attendance, which is associated with student performance that might affect risk of special education receipt, is measured as percent of days attended, was grand mean centered, and ranges from -94.5 to 5.5. Student mobility is included through a dichotomous variable of whether 


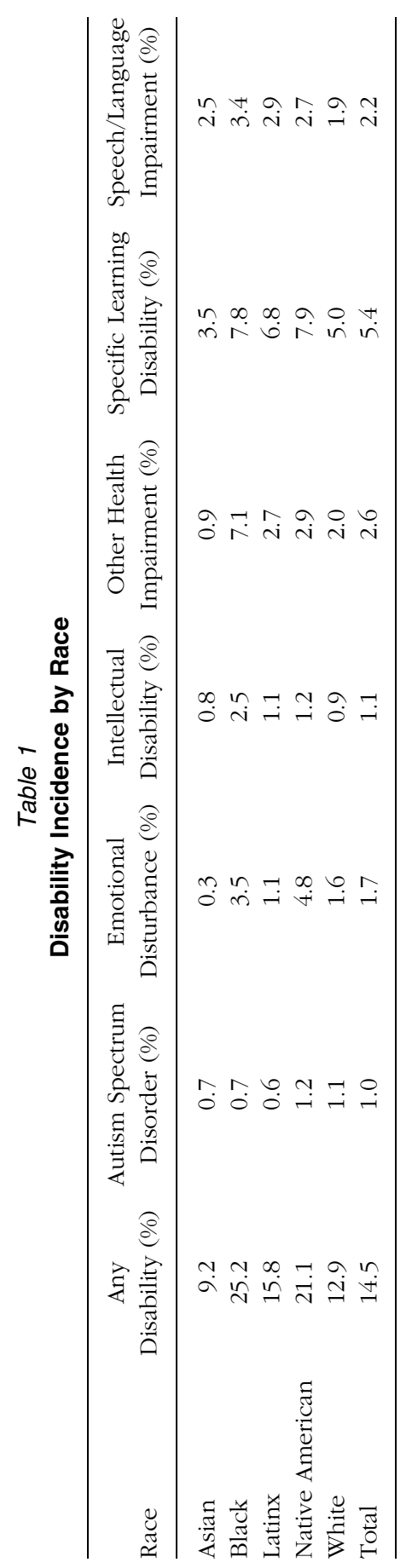




\begin{tabular}{lll}
\hline & Mean & Standard Deviation \\
\hline Student Level, $N=429,488$ & & \\
Male & 0.513 & 0.500 \\
Asian & 0.039 & 0.193 \\
Black & 0.107 & 0.309 \\
Latinx & 0.091 & 0.287 \\
Native American & 0.016 & 0.126 \\
English language learner & 0.076 & 0.264 \\
Free/reduced-price lunch & 0.397 & 0.489 \\
Attendance (mean centered) & 0.884 & 5.844 \\
Transferred in the past year & 0.028 & 0.166 \\
Reading proficiency level & 3.230 & 0.840 \\
Math proficiency level & 3.015 & 0.964 \\
Disability status & & \\
$\quad$ Any disability & 0.145 & 0.352 \\
Autism spectrum disorder & 0.010 & 0.101 \\
$\quad$ Emotional disorder & 0.017 & 0.131 \\
$\quad$ Intellectual disability & 0.011 & 0.105 \\
Other health impairment & 0.026 & 0.159 \\
$\quad$ Specific learning disability & 0.054 & 0.226 \\
Speech/language impairment & 0.022 & 0.146 \\
School level, $N=2,214$ & & \\
Proportion White & 0.756 & 0.264 \\
Proportion English language learners & 0.063 & 0.097 \\
Proportion free/reduced-price lunch & 0.411 & 0.235 \\
Average attendance (mean centered) & 0.000 & 0.059 \\
Proportion transferred in past year & 0.049 & 0.100 \\
Average reading proficiency level & 3.174 & 0.378 \\
Average math proficiency level & 2.935 & 0.443 \\
Proportion teachers of color & 0.044 & 0.108 \\
Proportion teachers with master's degrees & 0.514 & 0.193 \\
Proportion teachers with 5 or more years of experience & 0.831 & 0.120 \\
Proportion bilingual teachers & 0.006 & 0.032 \\
\hline & & \\
\hline
\end{tabular}

the student transferred schools in the past academic year $(0=$ did not transfer $1=$ transferred $)$. Math and reading achievement measures are reported from the statewide achievement test, the Wisconsin Knowledge and Concepts Examinations, and range from 1 to $4(1=$ minimal performance, $2=$ basic, $3=$ proficient, and $4=$ advanced ). The proficiency levels are used because full test scores are not available. Only $2.50 \%$ of all students are missing test scores; among students with disabilities this missingness ranges from $2.48 \%$ for autism spectrum disorder to $6.22 \%$ for emotional disturbance. Some students with significant deficits in cognitive functioning, 
adaptive behavior, and academic functioning are eligible to take an alternative test in lieu of the standardized tests; thus, the small numbers of missing data represent students with the most significant impairments. These data are excluded via listwise deletion, perhaps producing more conservative estimates. However, the outcome of interest focuses on students that have less significant, more subjectively diagnosed disabilities, who are unlikely to fall into the population of students that qualify for the alternative assessment.

The school-level independent variable of interest is the school racial composition, operationalized as the school proportion White. Although interactions between a student's race and the composition of same-race peers is also arguably of interest, such a measurement disregards the likely important role of White versus non-White peers, particularly with regard to racial marginalization within the school. School-level controls include aggregated measures of the individual-level variables for proportion ELL, proportion qualifying for FRL, as well as the mean proficiency level for math and reading tests (ranges from 1 to 4) and the school-level proportion of teachers of color, the proportion of teachers with masters' degrees, and the proportion of bilingual teachers are included, as all these may confound the relation between racial composition and racial disparities in special education receipt.

\section{Analytic Method}

I estimate the risk of special education receipt overall and the risk of receipt under each disability category through multilevel mixed-effects logistic regression models, which account for the nested nature of the student-level data within school-level data and allow for estimation of the binary outcomes. I use the xtmelogit command in Stata version 13.0 (StataCorp LP, 2013), with a random intercept for schools, and the Laplace approximation for improved computation time. The reference category in each model is "no disability."

The mixed-effects model predicting special education receipt is as follows:

$$
\operatorname{logit}\left(\pi_{i j}\right)=\beta_{0}+\beta_{1} X_{i j}+\beta_{2} X_{j}+u_{j}
$$

Here, the outcome $\pi_{i j}$ is a binary indicator of whether student $i$ receives special education receipt in school $j, \beta_{1} X_{i j}$ is a vector of all student-level variables (described above), $\beta_{2} X_{j}$ is a vector of all school-level variables (described above), and $\mathrm{u}_{\mathrm{j}}$ is the random effect for schools in this two-level random intercept model. Supplemental preliminary analyses (see supplementary tables in the online version of the journal) include a set of hierarchical models that build to the full models used in this study, allowing for a comparison of the results from this study with previous work on the relation of race to risk of special education receipt. Preliminary Model 1 includes 
gender and race at the individual level, to examine the disparities in incidence demonstrated by much of the literature (Coutinho et al., 2002). Preliminary Model 2 adds the remaining individual-level variables and school-level variables, allowing for a comparison with studies that include potential confounders using national datasets, especially those that examine school context (e.g., Hibel et al., 2010). The final model is the full model used for this study, which adds interactions between individual-level race and school-level racial composition to identify how race effects on the model vary by school racial composition.

\section{Results}

Results are reported in terms of the coefficients and, for more intuitive interpretation of logistic regression results, the exponentiated coefficients (baseline odds for constants, odds ratios for individual- and school-level covariates, and the ratios of odds ratios for interactions). ${ }^{1}$ See Table 3 for these estimates, and see Supplemental Tables 1 to 7 for the preliminary hierarchical models replicating the previous research on race and disability (available in the online version of the journal). The results are presented most intuitively in Figures 1 to 7 , which illustrate the predicted probabilities of each disability outcome by school proportion White, at the mean value for all other covariates in that model. The predicted probabilities were computed via the margins command in Stata version 13.0.

\section{All Disabilities}

The preliminary models (Supplemental Table 1), which replicate the previous research (e.g., Coutinho et al., 2002), suggest that when only race and gender are included in the model (Model 1, Supplemental Table 1), Black, Latinx, and Native American students have higher odds of special education receipt than their White peers, while Asian students have lower odds than their White peers. Model 2 (Supplemental Table 1), which replicates research using a richer set of covariates (e.g., Hibel et al., 2010), confirms that body of research, as Black, Latinx, and Asian students have lower odds of special education receipt than their White peers, once the confounders are taken into account.

In the full model presented in Table 3 and Figure 1, which includes the interactions between student-level race and school-level proportion White, I find that the relation between student-level race and special education varies across schools with different racial compositions. In the interactive model, the school-level main effect of proportion White applies only to White students; the coefficient is large and negative $(-1.089, p<.001)$, indicating that the risk of special education receipt is greater for White students in schools with fewer White peers. The coefficients for the interactions between race and school composition are all large, positive, and significant, negating the main effects of both individual-level race and school proportion 


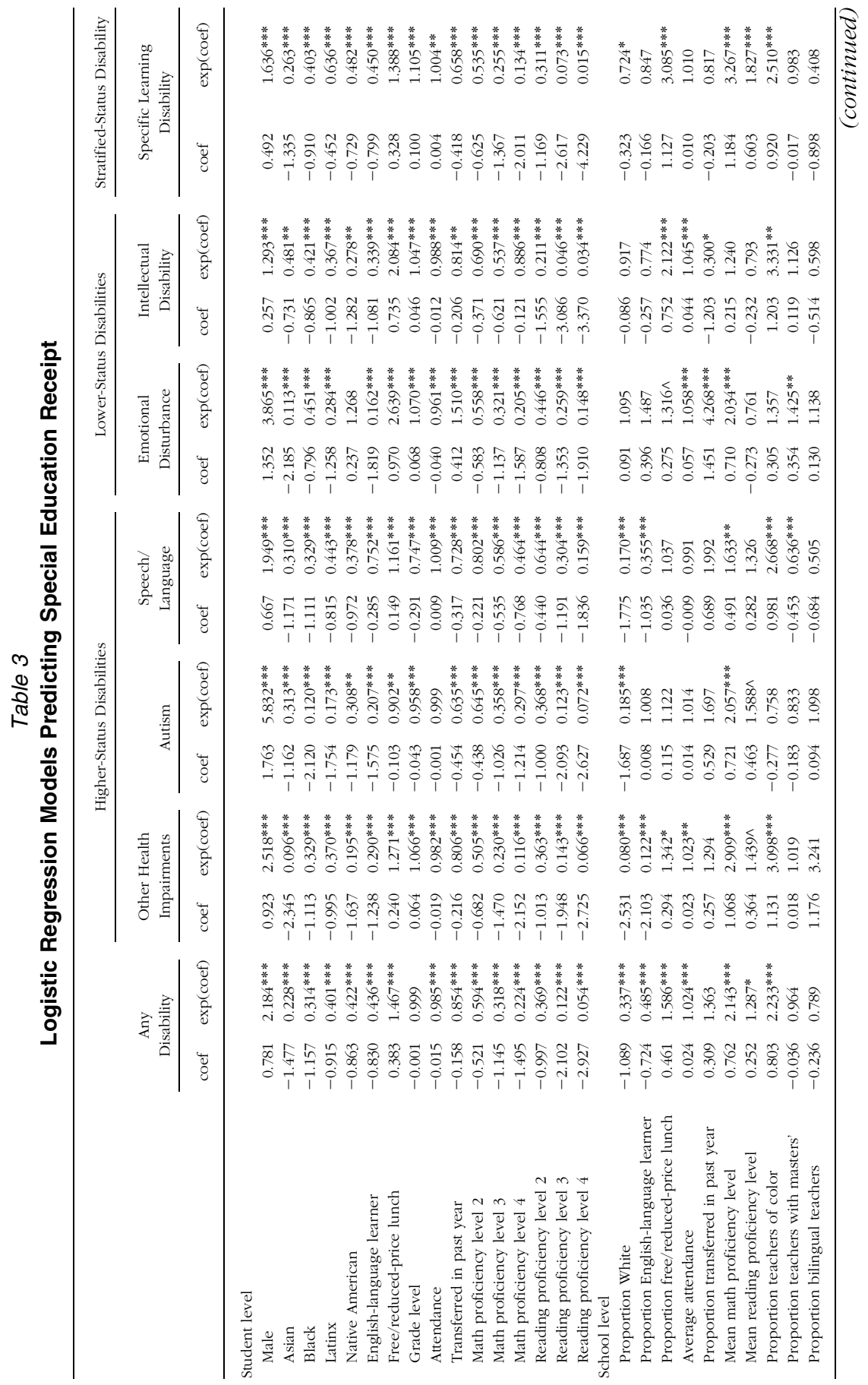




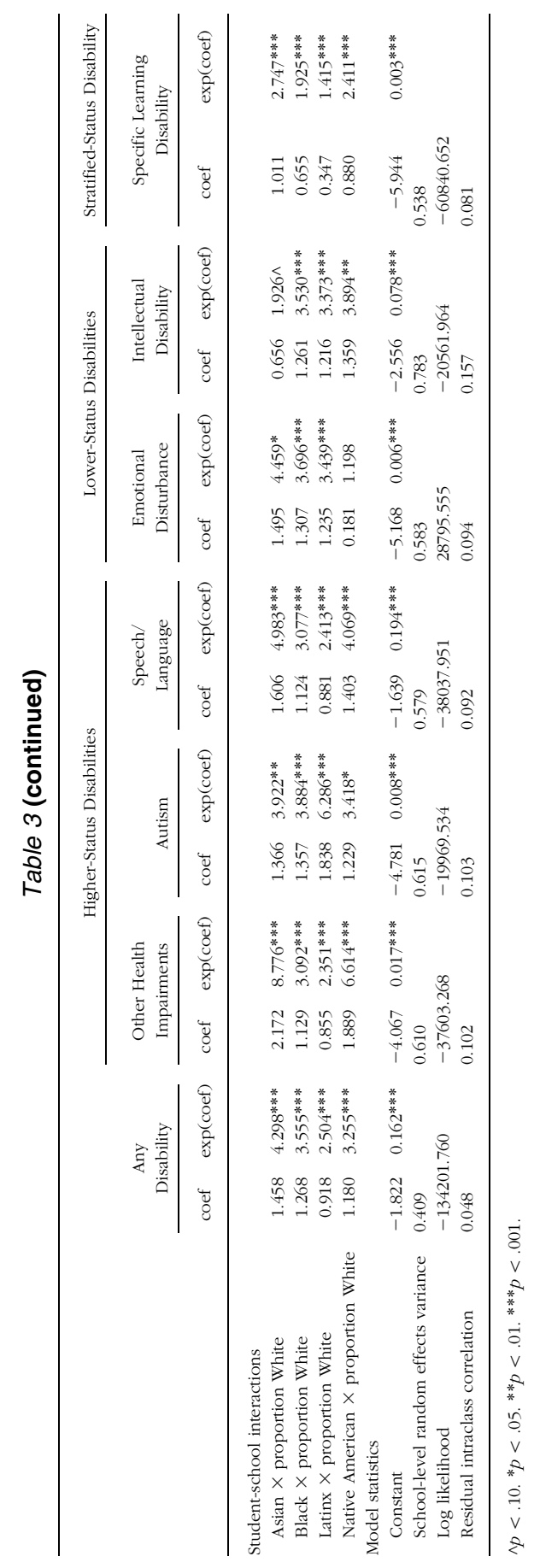




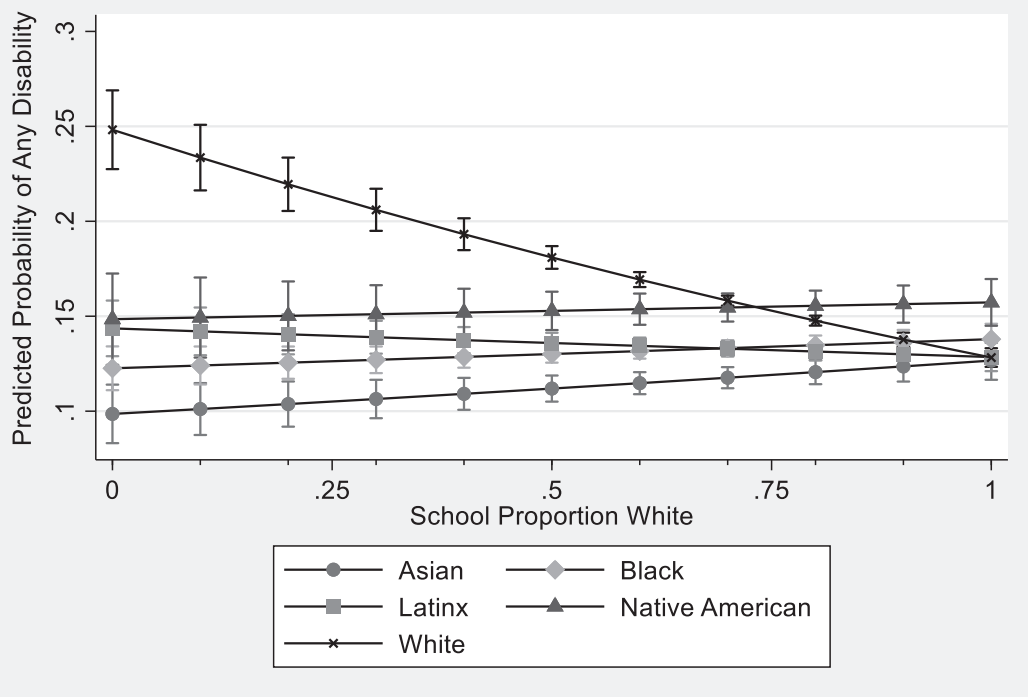

\section{Figure 1. Predicted probability of any disability.}

White for these non-White populations. As can be seen intuitively in Figure 1 , this means that school racial composition only matters for White students' odds of receipt of special education, as they experience a higher probability of special education receipt in schools with fewer White peers and decreasing probability as the school composition becomes more White. In contrast, all non-White students experience essentially no change in odds across schools with different racial compositions.

\section{Higher-Status Disabilities}

The higher status categories of disabilities include other health impairment (most frequently ADHD), autism spectrum disorder, and speech/language impairment. The preliminary models for these disability categories (Model 1 of Supplemental Tables 2, 3, and 4) generally follow the previous research findings that they are meant to replicate. When only race and gender are included, compared with White students' odds of special education receipt, Black and Native American students generally have higher odds of special education receipt, while Latinx students have similar odds for most higher-status categories, and Asian students have lower odds. Notably, for autism spectrum disorder (Supplemental Table 3), White students have higher odds than all other students, even in these simple models. When a richer set of covariates is included (Model 2 of Supplemental Tables 2, 3, 


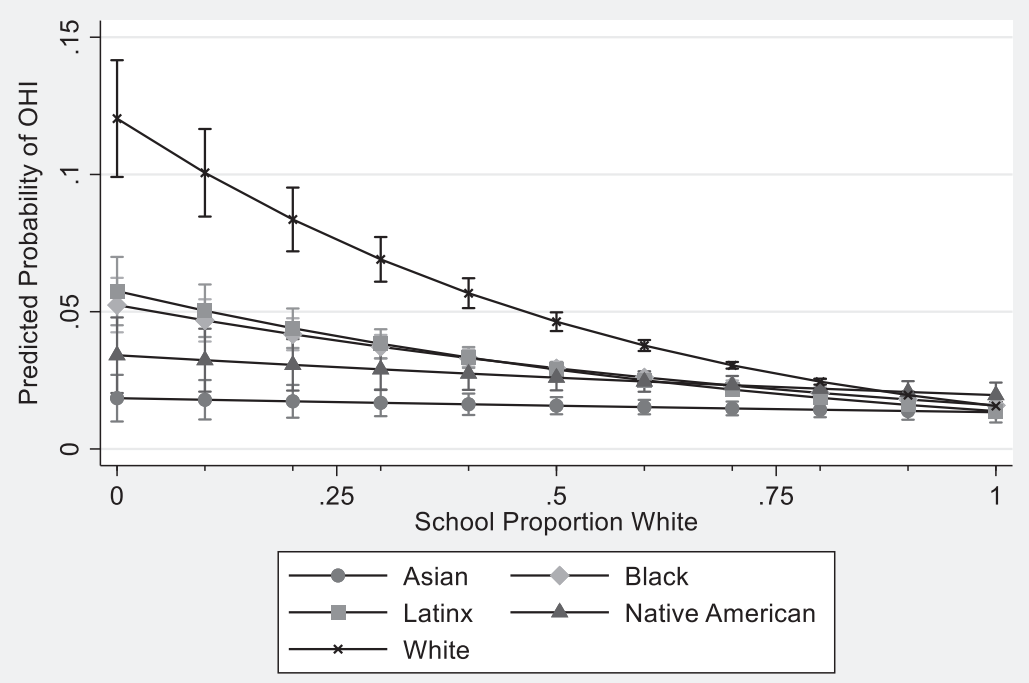

\section{Figure 2. Predicted probability of other health impairment.}

and 4), the findings here largely replicate the body of research that uses a similar set of variables, finding that White students' odds of special education receipt is higher than that of all their peers, excepting Asian and Native American students for the autism and speech/language outcomes.

The full models presented in Table 3 and Figures 2, 3, and 4, which include the cross-level interaction between school racial composition and student race, however, demonstrate that White students' higher odds of special education receipt for these categories is only in schools with fewer White students. This can be seen in the negative, significant coefficients for the main effects of race for the higher-status disabilities in Table 3. The coefficients for the main effect of school-level proportion White (which, in the fully interactive model, apply to the White students as the reference category) are negative and significant, indicating reduced odds of special education receipt for White students as the school proportion White increases. Meanwhile, the large, positive, significant interactions between student-level race and school-level racial composition indicate that Asian, Black, Latinx, and Native American students do not experience similar variation with school proportion White. The predicted probabilities (Figures 2, 3, and 4) illustrate these findings more intuitively: White students' increased probability of special education receipt for higher-status disabilities is only in schools with fewer White students and decreases as the proportion White increases. 


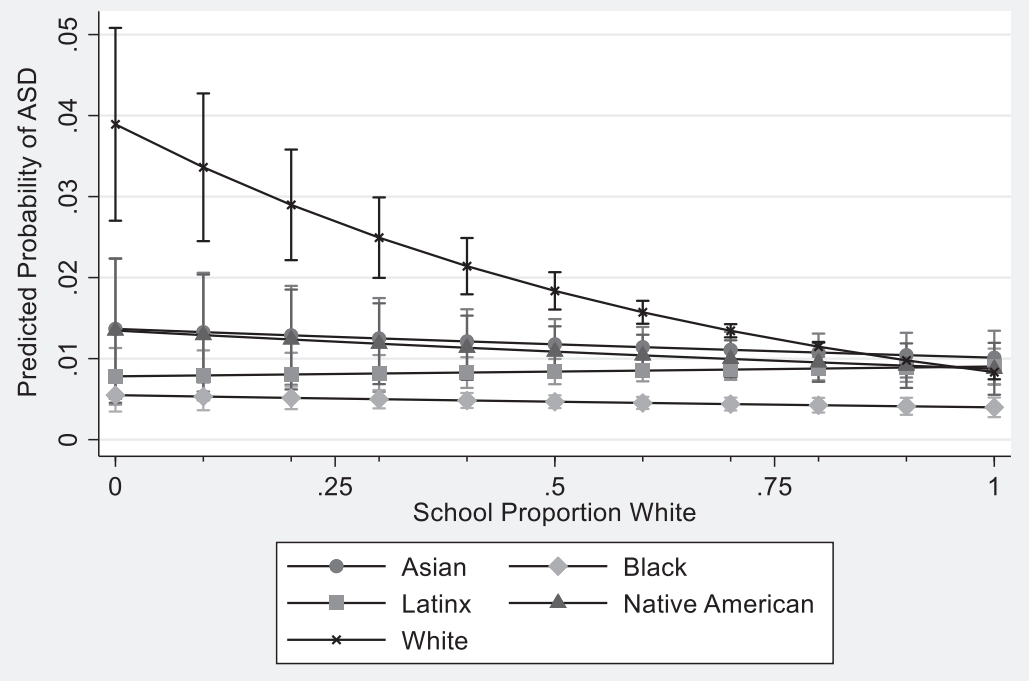

Figure 3. Predicted probability of autism spectrum disorder.

For Asian, Black, Latinx, and Native American students, there is essentially no change in their low probability of special education receipt for these categories of disability.

\section{Lower-Status Disabilities}

The two lower-status disabilities are emotional disturbance and intellectual disability. Again, for these outcomes, the two preliminary models generally follow the findings of the research that they are meant to replicate. Preliminary Model 1, found in each of the Supplemental Tables 5 and 6 for these outcomes, investigates only the effects of student-level race and gender on risk of special education receipt. These simple models show higher odds of emotional disturbance for Black and Native American students relative to their White peers, and they show higher odds of intellectual disability for Black, Latinx, and Native American students than for White students. Asian students, again, have lower odds of these lower-status disabilities than their White peers. Preliminary Model 2, found in Supplemental Tables 5 and 6 for these outcomes, seeks to replicate research using a richer set of school- and student-level covariates. Similar to that research, these preliminary models find that non-White students are not at higher risk of special education receipt than their White peers for these outcomes, excepting Native American students' risk of emotional disturbance. 


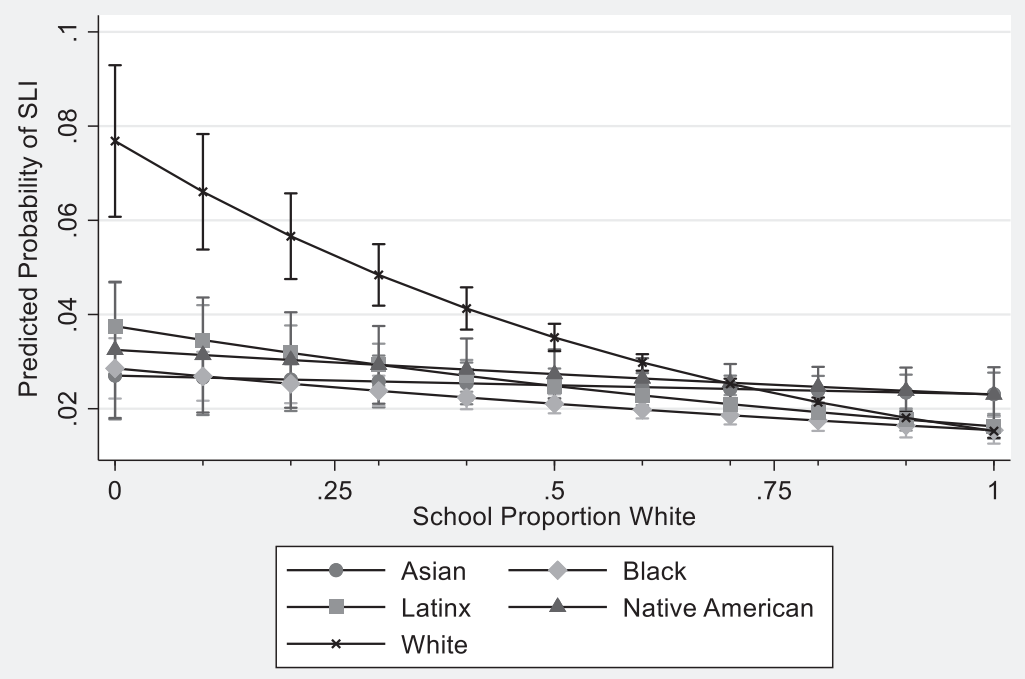

\section{Figure 4. Predicted probability of speech/language impairment.}

Table 3 and Figures 5 and 6 present the findings for the full models for lower-status disabilities: emotional disturbance and intellectual disability. Recall that for the higher-status disability categories, White students experience higher risk of special education receipt in schools with the fewest White peers, and their risk declines as the school composition becomes more White; meanwhile, for students of color, risk of special education receipt is lower and not correlated with school racial composition for the higherstatus disabilities. In contrast, the results for the lower-status disability categories of emotional disturbance and intellectual disability indicate that White students experience no change in risk of special education receipt and that students of color experience increasing risk of receipt as the school proportion White increases. Specifically, the main effects of race for Asian, Black, Latinx, and Native American students demonstrate lower risk of special education receipt in schools with the fewest White students for intellectual disability; the results for emotional disturbance are the same excepting Native American students. The main effects for school-level proportion White indicate that White students experience no change in risk of lower-status disability categories as the school racial composition changes. The coefficients for the interactions suggest that as the school proportion White increases, children of color experience substantively large, significantly increased risk of special education receipt (excepting Native American students for the outcome of 


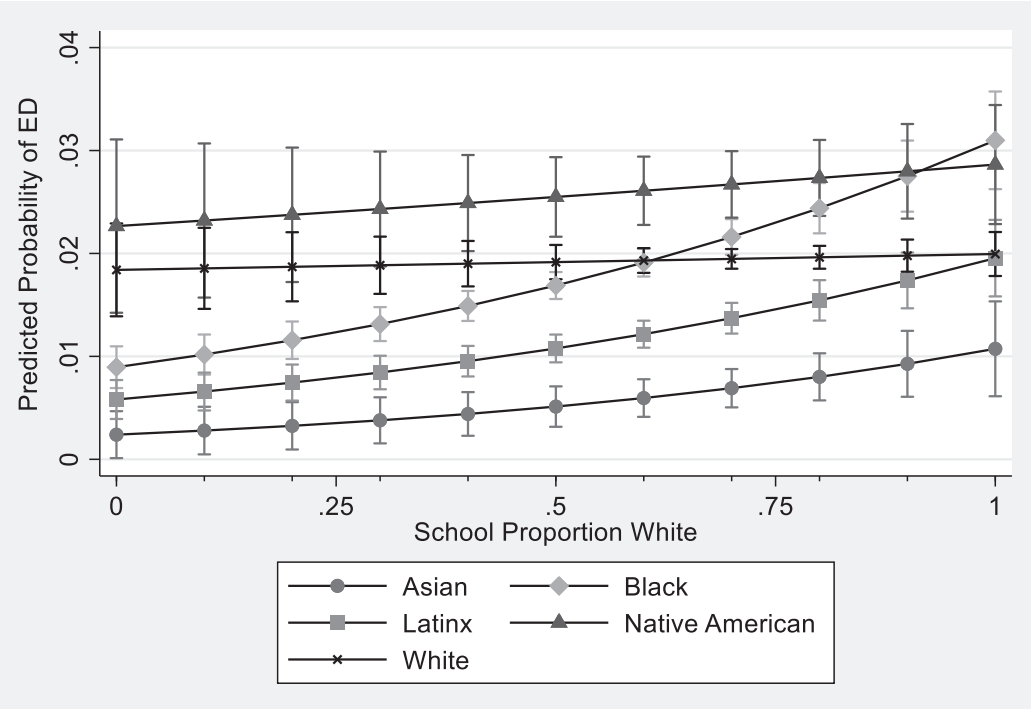

Figure 5. Predicted probability of emotional disturbance.

emotional disturbance and Asian students for the outcome of intellectual disability). Figures 5 and 6 illustrate these patterns more intuitively, showing that for the lower-status disability outcomes, Black and Latinx students-and less consistently Asian and Native American students-experience lower probability of special education receipt relative to their White peers only in schools with predominantly students of color, and their probability of receipt increases as the school composition becomes more White.

\section{Stratified-Status Disability}

For specific learning disability, the preliminary models again replicate the findings of the previous research: the model including only gender and race (Supplemental Table 7, Model 1) demonstrates higher odds of special education receipt for non-White students; the model including the richer set of covariates (Supplemental Table 7, Model 2) demonstrates lower odds for Asian, Black, and Latinx students than their White peers. The full model, which tests the interaction between school racial composition and student race, can be found in Table 3 and in Figure 7. The findings for this model are consistent with the outcomes for higher-status disabilities for White students and consistent with the lower-status disabilities for students of color. The negative main effects of race and the negative main effect of proportion White indicate that White students experience higher risk of special 


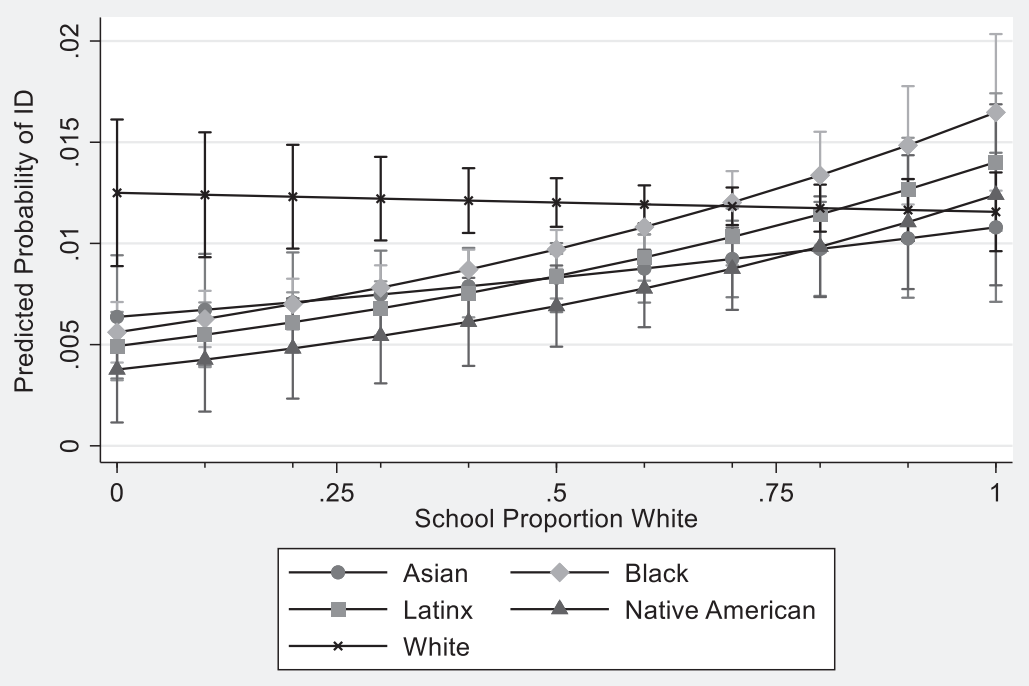

\section{Figure 6. Predicted probability of intellectual disability.}

education receipt in schools with the fewest White students and that this risk decreases as the school composition becomes less White. In contrast, the large, significant interaction effects for students of color not only offsets the main effects of race and racial composition; in fact, the direction of school composition effects reverses for students of color. The more intuitive predicted probabilities shown in Figure 7 illustrate that White students experience a similar pattern for specific learning disability as they do for higherstatus disabilities: decreasing risk as the school composition becomes more White; meanwhile, students of color experience a similar pattern for specific learning disability as they do for lower-status disabilities: increasing risk as the school composition becomes more White.

\section{Covariates}

The student- and school-level covariates included in Model 2 (in the supplemental tables) and in Model 3 (in the supplemental tables and in Table 3) also provide new data on the individual and contextual factors that are associated with receipt of special education. Across the models, ELL status is associated with lower risk of special education receipt, while qualifying for FRL is associated with higher risk of special education receipt for all categories excepting autism, which is negatively associated with FRL. While grade level and attendance are statistically significant, the effect sizes 


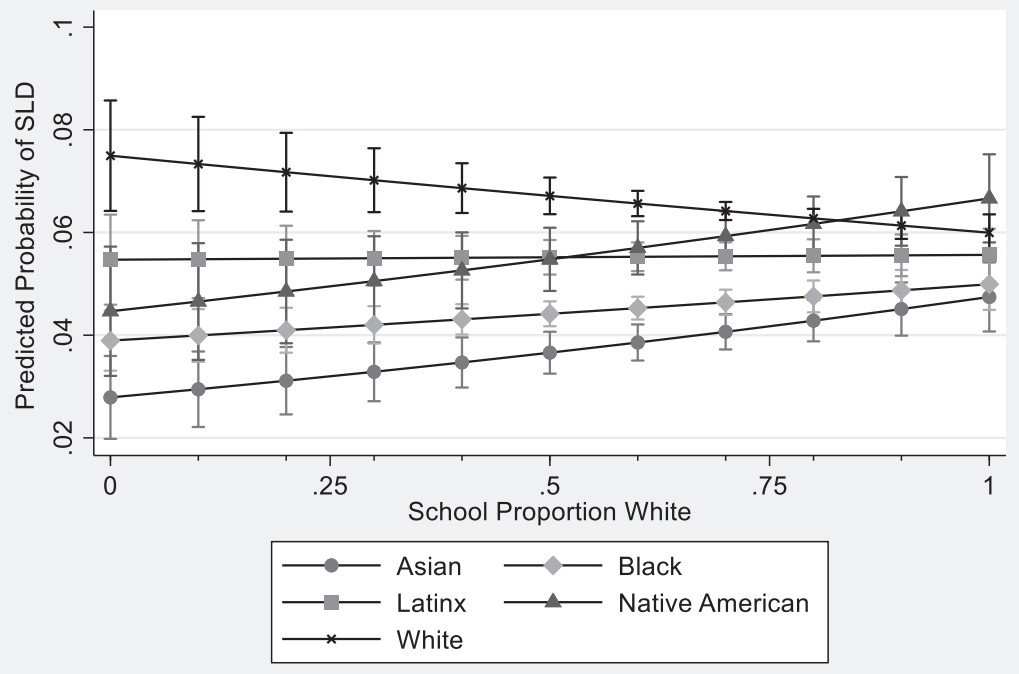

Figure 7. Predicted probability of specific learning disability.

are substantively meaningless. The estimates for student transfer status are negative except for emotional disturbance. Attending a school with a higher proportion of ELLs reduces risk of special education receipt only for higherstatus disabilities, while attending a school with more students qualifying for FRL increases risk for the lower- and stratified-status disability categories and for other health impairment. The proportion of recently transferred students is unrelated to special education receipt for most disabilities, but it is positively associated with risk of emotional disturbance and negatively associated with risk of intellectual disability. School-level academic achievement is associated with increased odds of a student receiving special education for every category excepting intellectual disability. The proportion of teachers of color is generally associated with increased odds of special education receipt. Teacher credentials and bilingualism are unassociated with student risk of special education, excepting the proportion of teachers with master's degrees being negatively associated with student risk of emotional disturbance and positively associated with risk of speech/language impairment.

\section{Discussion}

The results presented here suggest that categories of educational disability are constructed in ways that intersect with race, and that schools sort 
students into special education services in ways that may reinforce racial inequalities. Specifically, racial distinctiveness, or being surrounded by fewer same-race peers, appears to drive the salience of race in sorting into special education. While White students' risk of lower-status disabilities was unaffected by school racial composition, Black, Latinx, and, less consistently, Native American students experience increased risk of these disabilities when they are racially distinct within a school. In a near-mirror image, while non-White students experience little-to-no change in risk of higher-status disabilities in schools with different racial compositions, White students experience increased risk of these disabilities when they are racially distinct within a school. For specific learning disability-the stratified-status category-the moderation by school racial composition mirrors the higher-status categories for White students and the lower-status categories for students of color.

In sum, in the context of racial distinctiveness, White students who are struggling in school appear to maintain some relative advantages: Rather than being seen as simply low performing or unmotivated, they are more likely than their peers to be sorted into higher-status disabilities. These higher-status disabilities tend to provide greater teacher resources, accommodations that facilitate access to the general education curriculum, and a destigmatizing explanation for low performance. Meanwhile, in the context of racial distinctiveness, Black, Latinx, and, less consistently, Native American students who are struggling in school are sorted into lower-status disabilities, excluding them from the general education classroom, segregating them with other lower-performing peers, and allocating a stigmatizing label. While none of these disability categories are likely purely advantageous or disadvantageous, and the teachers and service providers working with these students undoubtedly aim to support students' success, the variation in status of disability can facilitate within-school stratification. The relation between race and disability demonstrated here suggests that categorical inequality processes (Domina et al., 2017) do not merely sort students into special and general education but that they sort students into different categories of disability, both creating and reinforcing racialized categories of disability and reinforcing racial inequality.

Moreover, the two preliminary models replicated the findings of both (a) the large body of disproportionality research that reports disparities in incidence by race and (b) the newer research that includes a richer set of covariates and multilevel modeling. This suggests that the findings here are not merely an artifact of this particular data set, at least in terms of the main individual- and school-level effects. It is only when the interactions between school-level racial composition and student-level race are included that the more complicated relationship between race and special education is revealed. In the interest of contributing to the knowledge of student- and school-level predictors of special education receipt, it is also worth briefly 
interpreting the estimates for covariates that are not the focus of this study, many of which have been included in previous disproportionality research. The finding that ELL status is associated with lower risk of special education receipt is consistent with previous research (Morgan et al., 2015), perhaps because when these students struggle, teachers perceive the difficulty as attributable to learning a new language. Qualifying for FRL is associated with a higher risk of special education receipt for all categories excepting autism, which is negatively associated with FRL. Consistent with previous findings (Morgan et al., 2016), it suggests, unsurprisingly, that lower socioeconomic status is associated with increased schooling challenges that might result in special education receipt. The inverse relationship for autism, then, provides some support for this category being conceptualized as a higherstatus disability. The largely negative estimates for student transfer status likely reflect the challenges of testing and identifying disabilities among a more mobile population.

The school-level predictors, too, contribute to the body of knowledge around special education receipt. The findings presented here, in which higher school-level academic achievement is associated with higher risk of all disabilities except for intellectual disability, is largely consistent with the findings by Hibel et al. (2010) and likely due to the increased risk of identifying children as struggling when they stand out among higherperforming peers. The finding of a positive relationship between the risk of special education receipt and the school-level proportion of teachers of color is expanded upon by Fish (2019) and may be due to teachers of color perceiving their students more positively (Bates \& Glick, 2013; Irizarry, 2015; Pigott \& Cowen, 2000), seeing higher potential and thus greater need for services among struggling students. Other school-level predictors are less consistent with existing literature, such as the positive association between school proportion FRL and risk of lower- and stratified-status categories of disability. This may reflect the lower level of resources available at these schools, meaning that fewer intervention options are available outside of special education and also that these less-advantaged schools might be more likely to sort students into lower-status categories of disability.

\section{Possible Mechanisms}

While findings suggest that racial distinctiveness within a school enhances the role of race in sorting into disability categories, the mechanisms of this process cannot be addressed by the data and methods used here. Existing research suggests several possible ways that school racial composition shapes racial inequalities in special education; however, some of these potential mechanisms are better supported by the findings than others. 


\section{Teachers' Perceptions of Students}

Special education placement reflects, in part, a referral by a teacher who perceives the students as struggling in comparison with (a) their expectations of the student and (b) their peers' performance (Gerber \& Semmel, 1984; Mamlin \& Harris, 1998). The teacher's suspicion of disability is thus informed by comparisons with peers. Indeed, Hibel et al. (2010) find that students have a higher risk of special education receipt when they attend schools with higher-achieving peers and more White peers, which they suggest makes low-performing students stand out more, known as frog pond effects (Davis, 1966). Yet it is also possible that teacher evaluations of student skills may be based on "demographic statuses linked to achievement [that act as] the trigger for the comparison processes" (Crosnoe, 2009). In this way, the racial biases that unintentionally affect teachers' suspicions of exceptionality (Fish, 2017) may become more salient when a student stands out racially among his peers. Thus, racial distinctiveness might enhance racial bias in teachers' perceptions of students, exacerbating biased perceptions of students of color as having lower-status disabilities, such as emotional disturbance (Fish, 2017), as well as biased perceptions of White students' academic challenges as reflecting higher-status disabilities, such as ADHD (Fish, 2017). Indeed, the findings here suggest that school racial composition might matter for racialized sorting into disability through such racialized frog pond effects.

It is also possible that teacher racial bias varies across schools of differing racial compositions because of staff selection into these schools. For instance, a teacher or other school staff member that has more negative perceptions of students of color would likely choose to work in a school with fewer students of color. Such a teacher may not adequately support children of color to prevent disability identification and also may advocate for services under lower-status disability categories that are more exclusionary. Similarly, a teacher who chooses to teach in a school with more students of color may be more likely to perceive these students more favorably or may have a political ideology rooted in racial equity. As a result, such a teacher may be less likely to advocate for lower-status categories of disability for students of color or may seek to reduce the placement of children of color in special education more broadly.

\section{Racial Political Climate}

Second, as is suggested by both empirical findings (Eitle, 2002) and theory (Ferri \& Connor, 2005; Mccall \& Skrtic, 2009), racial composition may matter for sorting into special education by creating racial political climates that facilitate racialized sorting (Eitle, 2002; Ferri \& Connor, 2005; Hibel et al., 2010; Mccall \& Skrtic, 2009). Schools with more students of color may be less likely to place students in special education because of policy- and parent- 
led pressure to reduce overrepresentation of students of color in special education, as higher numbers of families of color may support effective mobilization against placement (Eitle, 2002; Hibel et al., 2010). Alternatively, racial composition may engender racialized competition over scarce educational resources, as White families may perceive students of color as a threat to their own children's success (Blalock, 1967; Blumer, 1958; Bobo, 1983), for instance, taking the teachers' attention away from their own children. While teachers and other staff members in eligibility meetings base diagnoses on assessment tools, these parental pressures may affect their interpretations of assessments (Lipsky, 1971). Research on other categorical inequality processes supports this mechanism, as findings suggest that advantaged families advocate for academic tracking in schools with more racial and socioeconomic diversity (Domina, Hanselman, Hwang, \& McEachin, 2016; Staiger, 2004; Wells \& Serna, 1996). Thus, in the context of racial distinctiveness of children of color, White parents may pressure school staff to reduce the perceived impact of children of color on the classroom (e.g., by complaining that particular students are taking too much of the teacher's time), facilitating placement into special education for more exclusionary disability categories.

When their own children are racially distinct, in contrast, White families with low-performing children may advocate for higher-status disabilities, which allocate more teacher resources to their children and also distinguish and separate them from merely low-performing peers (McGrath \& Kuriloff, 1999; Noguera, 2001; Wells \& Serna, 1996). This explanation is particularly compelling in the context of schools with more children of color, as resources tend to be more scarce in general in these schools, which likely explains the overall pattern of lower levels of special education receipt in these schools (Hibel et al., 2010). This relative scarcity may increase White families' likelihood of advocating for higher-status disabilities, which would provide extra teacher resources and supports within a lower-resourced environment.

\section{Student Need for Special Education Services}

Finally, school racial composition may directly affect the development of skills and behaviors through social-psychological mechanisms, shaping student need for special education services. Some research suggests that attending a school with a high proportion of students of color harms the outcomes of students of color (Berends, Lucas, \& Penaloza, 2008; Hanushek \& Rivkin, 2009; Mickelson, Bottia, \& Lambert, 2013). Yet other research suggests that attending schools with more same-race peers has positive effects for students of color, such as more positive academic orientations and school attachment (Goldsmith, 2004; Tyson et al., 2005), lower levels of social isolation (Tyson et al., 2005), and protection from stereotype threat (Hanselman et al., 2014). The findings here are partially consistent with the latter set of research, as for 
students of color having more same-race peers is an asset that may work to support lower odds of lower-status disabilities. Yet that research does not shed light on the opposite pattern found here among White students, suggesting that other explanations are more likely for the overall findings.

\section{Limitations}

This study is not without limitations. One problem, which is shared by many observational studies of racial disproportionality in special education (Hibel et al., 2010; Morgan et al., 2015; Shifrer et al., 2011), is that achievement data are likely partially endogenous. Children with disabilities are often identified because they are low performers, and after placement in special education, and even in the years preceding placement while alternative interventions are attempted, they receive instruction that may actually further limit their academic achievement. If factors such as teacher expectations and perceptions affect racial disparities in identification of disabilities, as is consistent with the findings presented here, then these same mechanisms likely affect achievement throughout schooling (Jussim, Eccles, \& Madon, 1996; McKown \& Weinstein, 2002; Rosenthal \& Jacobson, 1968). However, academic skills also likely play a role in whether a child is identified as having a disability. This study is observational and does not speak to causality. The decision to include the test scores in the models is imperfect, yet it is less imperfect than excluding these data on academic achievement. Moreover, the body of literature that examines a rich set of covariates as predictors of special education placement includes these variables; thus, including these variables allows for comparisons with that body of research. I also conducted a set of analyses that exclude the test scores (available on request), which produced interaction effects in similar directions as the results presented here.

Second, the data present some limitations in terms of generalizability; specifically, the patterns observed may be specific to the Wisconsin context. Indeed, Wisconsin has a very high proportion of White population. While the size of the data set alleviates concerns about the model estimates presented here, the state may have a particular political and cultural context that shapes the findings. However, these generalizability concerns are largely ameliorated by the findings that the preliminary models (presented in the supplemental tables) generally parallel the findings of the nationally representative studies they are meant to replicate. Unlike the national samples used in many studies (Hibel et al., 2010; Morgan et al., 2015; Shifrer et al., 2011), the size and completeness of the data allow for investigation of racial disparities across all documented racial groups, including Native American students, and all disability categories of interest. Additionally, disproportionality scholars argue that these patterns are inherently local and that state and local analyses are critical to understanding racial disparities in special 
education (Artiles, 2011; Donovan \& Cross, 2002). This suggests the need for replications of this research in other state contexts.

\section{Implications}

\section{Racial Disproportionality in Special Education}

In 2016, the Obama administration issued Equity in Individuals with Disabilities Education Act (IDEA) regulations, which required "a common standard for identifying significant disproportionality in representation of students within special education," as well as segregated settings and disciplinary actions; the rule also required school districts to address disproportionality due to under- or overidentification (U.S. Department of Education, Office of Special Education and Rehabilitative Services, \& Office of Special Education Programs, 2016). As of the time of this article being written, the status of this provision is contested: The U.S. Education secretary Betsy DeVos delayed the implementation of the Equity in IDEA rule (Voulgarides, 2018), but this delay was ruled illegal (Axelrod, 2019). While the attempted delay suggests a minimization of the civil rights issue and an emphasis on states' rights by the U.S. Department of Education (Voulgarides, 2018), it appears that even the original rule, meant to increase racial equity, had the potential to oversimplify the nature of the problem. My findings suggest that the relation between race and special education receipt varies by category of disability and by school context, suggesting a more complex process-with more complex implications (Kauffman \& Anastasiou, 2019) — than the current debate of overrepresentation (e.g., Skiba et al., 2005) versus underrepresentation (e.g., Morgan et al., 2015) of children of color in special education. Indeed, a determination of "overrepresentation" of a racial group that ignores individual- and school-level confounders may inadvertently harm children by denying them services.

While research on the effects of special education on child outcomes presents mixed findings (Hanushek, Kain, \& Rivkin, 2002; Morgan et al., 2010; Shifrer et al., 2013), the current findings, in conjunction with the typology of disability status, suggest that policy should not simply focus on schools' referrals and qualifications of students of color with educational disabilities. Rather, further research should investigate the effects of these services for students, to determine the full implications of which students are sorted into special education. Meanwhile, rather than discouraging teachers from referring students of color to special education testing, students might be better served by both (a) reducing inequalities that might lead to disability identification, such as improved access to high-quality early-childhood education that would improve skills at school-entry, and (b) making special education service provision as equitable, high-quality, and inclusive as possible, so that special education services support access and success for all students with disabilities. While implementation of the Equity in IDEA rule would 
help establish the U.S. Department of Education's commitment to racial equity, future policies need to properly account for the complexities of identifying disabilities and appropriately supporting students.

\section{School Racial Context and Categorical Inequality}

The results presented here have implications not only for the scholarly understanding of racial disproportionality in special education but also for the literature on the role of school racial composition in categorical inequality processes. The majority of the literature provides evidence that racially integrated schools reduce racial achievement gaps and improve the achievement of students of color (Berends et al., 2008; Borman et al., 2004; Grissmer, Flanagan, \& Williamson, 1998; Guryan, 2004; Hanushek \& Rivkin, 2009; Mickelson et al., 2013). Yet I find that White students secure more withinschool advantages when they attend schools with more peers of color, and that students of color are sorted into more disadvantaged positions when they attend schools with more White students. Racial integration is a presumed social good that supports racial equity. However, my findings align with a small body of work suggesting that some processes in more racially diverse schools may also exacerbate some racial inequalities (Hanselman et al., 2014; Tyson, 2011). Specifically, my findings suggest that racial distinctiveness may exacerbate categorical inequality and that attending a school with more same-race peers may provide some benefits for children of color. Given the advantages of integrated schools for racial equity more broadly (Berends et al., 2008; Borman et al., 2004; Grissmer et al., 1998; Guryan, 2004; Hanushek \& Rivkin, 2009; Mickelson et al., 2013), this suggests a need for a better understanding of how inequality is maintained even in more diverse schools.

\section{Notes}

I thank Adam Gamoran, Myra Marx Ferree, and William Carbonaro for their helpful advice and feedback, as well as the feedback and support of my writing group: Shani Evans, Angela Frederick, Laura Mauldin, Jennifer Pearson, Carrie Shandra, and Dara Shifrer. This research was supported by the Institute of Education Sciences, U.S. Department of Education, through Award \#R305B090009 to the University of WisconsinMadison; by the National Science Foundation, through Award \#1335217 to the author; and by the National Academy of Education, through the National Academy of Education/Spencer Dissertation Fellowship to the author. The article's contents are solely the responsibility of the author and do not represent the official views of any supporting agency.

Supplemental material is available for this article in the online version of the journal.

${ }^{1}$ Interpreting logistic regression results: For the main effects, a positive (or negative) coefficient is exponentiated to an odds ratio greater than (or less than) 1.00 , indicating an increase (or decrease) in the odds of a student receiving special education, for each unit increase in the corresponding predictor variable, holding all other variables in the model constant, as compared with students without that unit increase. For example, in Table 3, in the column displaying results for Any Disability, the coefficient for the student-level variable, Black, is -1.157 , which is exponentiated to an odds ratio of 0.314 . Thus, holding all 


\section{Fish}

other variables constant, Black students experience a decrease in odds of special education receipt for any disability, as compared with White students. The school-level variables generally follow a similar interpretation. The inclusion of interactions necessitates a different interpretation for school racial composition and interaction estimates. The main effect of Proportion White is the change in log odds of special education receipt when the school proportion White changes from 0 to 1 , for White students only; meanwhile, the interaction effect for Proportion White by student race is the corresponding change in log odds for each non-White racial group. For example, under the outcome of Any Disability in Table 3, the coefficient for Proportion White means that White students experience a decrease in $\log$ odds of special education receipt of -1.089 (exponentiated to an odds ratio of 0.337 ) when they experience a change from a school with no White students to a school with all White students. The estimate for the interaction of Black $\times$ Proportion White is 1.268 , meaning that with the corresponding change in school racial composition, Black students experience a change in log odds of $(-1.089+1.268)=0.179$ (exponentiated to an odds ratio of 1.196). The exponentiated coefficient for the interaction term is the ratio of the odds ratio for racial composition for White students over the odds ratio for racial composition for Black students: 1.196/0.337 $=3.555$.

\section{ORCID iD}

Rachel Elizabeth Fish (iD) https://orcid.org/0000-0002-5720-021X

\section{References}

Artiles, A. J. (2011). Toward an interdisciplinary understanding of educational equity and difference: The case of the racialization of ability. Educational Researcher, 40, 431-445. doi:/10.3102/0013189X11429391

Axelrod, T. (2019, March 8). Federal judge rules DeVos illegally delayed Obama-era special education rule. The Hill. Retrieved from https://thehill.com/homenews/ administration/433312-federal-judge-rules-devos-illegally-delayed-obama-eraspecial

Bal, A., Betters-Bubon, J., \& Fish, R. E. (2017). A multilevel analysis of statewide disproportionality in exclusionary discipline and the identification of emotional disturbance. Education and Urban Society. Advanced online publication. doi: $10.1177 / 0013124517716260$

Bates, L. A., \& Glick, J. E. (2013). Does it matter if teachers and schools match the student? Racial and ethnic disparities in problem behaviors. Social Science Research, 42, 1180-1190. doi:10.1016/j.ssresearch.2013.04.005

Berends, M., Lucas, S. R., \& Penaloza, R. V. (2008). How changes in families and schools are related to trends in Black-White test scores. Sociology of Education, 81, 313-344. doi:10.1177/003804070808100401

Blalock, H. M. (1967). Toward a theory of minority-group relations. New York, NY: Wiley

Blanchett, W. J. (2010). Telling it like it is: The role of race, class, and culture in the perpetuation of learning disability as a privileged category for the White middle class. Disability Studies Quarterly, 30. doi:10.18061/dsq.v30i2.1233

Blumer, H. (1958). Race prejudice as a sense of group position. Pacific Sociological Review, 1, 3-7. doi:10.2307/1388607

Bobo, L. (1983). Whites' opposition to busing: Symbolic racism or realistic group conflict? Journal of Personality and Social Psychology, 45, 1196-1210. doi:10.1037/ 0022-3514.45.6.1196 
Borman, K. M., Eitle, T. M., Michael, D., Eitle, D. J., Lee, R., Johnson, L., . . Shircliffe, B. (2004). Accountability in a postdesegregation era: The continuing significance of racial segregation in Florida's schools. American Educational Research Journal, 41, 605-631. doi:10.3102/00028312041003605

Braddock, J. H. I. (1990). Tracking the middle grades: National patterns of grouping for instruction. The Phi Delta Kappan, 71, 445-449.

Brinkman, W. B., Sherman, S. N., Zmitrovich, A. R., Visscher, M. O., Crosby, L. E., Phelan, K. J., \& Donovan, E. F. (2009). Parental angst making and revisiting decisions about treatment of attention-deficit/hyperactivity disorder. Pediatrics, 124, 580-589. doi:10.1542/peds.2008-2569

Brown, T. E. (2011, September 16). The mysteries of ADD and high IQ. Retrieved from Psychology Today website: https://www.psychologytoday.com/blog/the-mys teries-add/201108/the-mysteries-add-and-high-iq

Charman, T., Pickles, A., Simonoff, E., Chandler, S., Loucas, T., \& Baird, G. (2011). IQ in children with autism spectrum disorders: Data from the Special Needs and Autism Project (SNAP). Psychological Medicine, 41, 619-627. doi:10.1017/ S0033291710000991

Connor, D. (2005). Integration and inclusion: A troubling nexus: Race, disability, and special education. Journal of African American History, 90, 107-127. doi:10.1086/JAAHv90n1-2p107

Conrad, P. (1976). Identifying hyperactive children: The medicalization of deviant behavior. Lexington, MA: D.C. Heath.

Cormier, E. (2012). How parents make decisions to use medication to treat their child's ADHD: A grounded theory study. Journal of the American Psychiatric Nurses Association, 18, 345-356. doi:10.1177/1078390312466918

Coutinho, M., Oswald, D., \& Best, A. (2002). The influence of sociodemographics and gender on the disproportionate identification of minority students as having learning disabilities. Remedial and Special Education, 23, 49-59. doi:10.1177/ 074193250202300107

Crosnoe, R. (2009). Low-income students and the socioeconomic composition of public high schools. American Sociological Review, 74, 709-730. doi:10.1177/ 000312240907400502

Davis, J. A. (1966). The campus as a frog pond: An application of the theory of relative deprivation to career decisions of college men, 72, 17-31. doi:10.2307/2775756

Domina, T., Hanselman, P., Hwang, N., \& McEachin, A. (2016). Detracking and tracking up: Mathematics course placements in California middle schools, 2003-2013. American Educational Research Journal, 53, 1229-1266. doi:10.3102/000283121 6650405

Domina, T., Penner, A., \& Penner, E. (2017). Categorical inequality: Schools as sorting machines. Annual Review of Sociology, 43, 311-330. doi:10.1146/annurev-soc060116-053354

Donovan, M. S., \& Cross, C. (2002). Minority students in special and gifted education. Washington, DC: National Academies Press.

Dudley-Marling, C. C. (2004). The social construction of learning disabilities. Journal of Learning Disabilities, 37, 482-489. doi:10.1177/00222194040370060201

Dunn, L. M. (1968). Special education for the mildly retarded-is much of it justifiable? Exceptional Children, 35(1), 5-22.

Edwards, L. (2016). Homogeneity and inequality: School discipline inequality and the role of racial composition. Social Forces, 95, 55-76. doi:10.1093/sf/sow038

Eitle, T. M. (2002). Special education or racial segregation: Understanding variation in the representation of Black students in educable mentally handicapped programs. Sociological Quarterly, 43, 575-605. doi:10.1111/j.1533-8525.2002.tb00067.x 
Erevelles, N., \& Minear, A. (2010). Unspeakable offenses: Untangling race and disability in discourses of intersectionality. Journal of Literary \& Cultural Disability Studies, 4, 127-145. doi:10.3828/jlcds.2010.11

Eyal, G. (2013). For a sociology of expertise: The social origins of the autism epidemic 1. American Journal of Sociology, 118, 863-907. doi:10.1086/668448

Ferri, B., \& Connor, D. (2005). Tools of exclusion: Race, disability, and (re) segregated education. Teachers College Record, 107, 453-474. doi:10.1111/j.14679620.2005.00483.x

Fish, R. E. (2017). The racialized construction of exceptionality: Experimental evidence of race/ethnicity effects on teachers' interventions. Social Science Research, 62, 317-334. doi:10.1016/j.ssresearch.2016.08.007

Fish, R. E. (2019). Teacher race and racial disparities in special education. Remedial and Special Education. Advanced online publication. doi:10.1177/07419325 188104

Garfunkel, L. C., Kaczorowski, J., \& Christy, C. (2007). Pediatric clinical advisor: Instant diagnosis and treatment (2nd ed.). Philadelphia, PA: Mosby.

Gerber, M. M., \& Semmel, M. I. (1984). Teacher as imperfect test: Reconceptualizing the referral process. Educational Psychologist, 19, 137-148. doi:10.1080/ 00461528409529290

Gillung, T. B., \& Rucker, C. N. (1977). Labels and teacher expectations. Exceptional Children, 43, 464-465.

Goldsmith, P. A. (2004). Schools' racial mix, students' optimism, and the Black-White and Latino-White achievement gaps. Sociology of Education, 77, 121-147. doi: $10.1177 / 003804070407700202$

Gottlieb, J., \& Alter, M. (1994). An analysis of referrals, placement, and progress of children with disabilities who attend New York City public schools. New York: New York University.

Grandin, T. (2008). The way I see it: A personal look at autism and Asperger's. Arlington, TX: Future Horizons.

Grice, K. (2002). Eligibility under IDEA for other health impaired children. School Law Bulletin, Retrieved from http://www.pathfinder-nd.org/pdf/Equality OHIIDEA.pdf

Grissmer, D., Flanagan, A., \& Williamson, S. (1998). Why did the Black-White score gap narrow in the 1970s and 1980s. In C. Jencks \& M. Phillips (Eds.), The BlackWhite test score gap (pp. 182-228). Washington, DC: Brookings Institution Press.

Guryan, J. (2004). Desegregation and Black dropout rates. American Economic Review, 94, 919-943. doi:10.1257/0002828042002679

Hanselman, P., Bruch, S. K., Gamoran, A., \& Borman, G. D. (2014). Threat in context: School moderation of the impact of social identity threat on racial/ethnic achievement gaps. Sociology of Education, 87, 106-124. doi:10.1177/ 0038040714525970

Hanushek, E. A., Kain, J. F., \& Rivkin, S. G. (2002). Inferring program effects for special populations: Does special education raise achievement for students with disabilities? Review of Economics and Statistics, 84, 584-599. doi:10.2307/1602496

Hanushek, E. A., \& Rivkin, S. G. (2009). Harming the best: How schools affect the Black-White achievement gap. Journal of Policy Analysis and Management, 28, 366-393. doi:10.1002/pam.20437

Harry, B., \& Anderson, M. (1994). The disproportionate placement of African American males in special education programs: A critique of the process. Journal of Negro Education, 63, 602-619. doi:10.2307/2967298 
Harry, B., \& Klingner, J. (2007). Why are so many minority students in special education? Understanding race \& disability in schools. New York, NY: Teachers College Press.

Hibel, J., Farkas, G., \& Morgan, P. L. (2010). Who is placed into special education? Sociology of Education, 83, 312-332. doi:10.1177/0038040710383518

Hibel, J, \& Jasper, A. D. (2012). Delayed special education placement for learning disabilities among children of immigrants. Social Forces, 91, 503-530. doi:10.1093/ sf/sos092

Irizarry, Y. (2015). Selling students short: Racial differences in teachers' evaluations of high, average, and low performing students. Social Science Research, 52, 522538. doi:10.1016/j.ssresearch.2015.04.002

Jussim, L., Eccles, J., \& Madon, S. (1996). Social perception, social stereotypes, and teacher expectations. In M. P. Zanna (Ed.), Advances in experimental social psychology (Vol. 28, pp. 281-388). San Diego, CA: Academic Press. doi:10.1016/ S0065-2601(08)60240-3

Kauffman, J. M., \& Anastasiou, D. (2019). On cultural politics in special education: Is much of it justifiable? Journal of Disability Policy Studies. Advanced online publication. doi:10.1177/1044207318822262

King, M. D., Jennings, J., \& Fletcher, J. M. (2014). Medical adaptation to academic pressure: Schooling, stimulant use, and socioeconomic status. American Sociological Review, 79, 1039-1066. doi:10.1177/0003122414553657

Lipsky, M. (1971). Street-level bureaucracy and the analysis of urban reform. Urban Affairs Quarterly, 6, 391-409. doi:10.1177/107808747100600401

Liu, K.-Y. K., King, M. M., \& Bearman, P. S. P. (2010). Social influence and the autism epidemic. American Journal of Sociology, 115, 1387-1434. doi:10.1086/651448

Lloyd, J. W., Kauffman, J. M., Landrum, T. J., \& Roe, D. L. (1991). Why do teachers refer pupils for special education? An analysis of referral records. Exceptionality, 2, 115-126. doi:10.1080/09362839109524774

Losen, D., \& Welner, K. (2001). Disabling discrimination in our public schools: Comprehensive legal challenges to inappropriate and inadequate special education services for minority children. Harvard Civil Rights-Civil Liberties Law Review, 36, 407.

Lucas, S., \& Berends, M. (2002). Sociodemographic diversity, correlated achievement, and de facto tracking. Sociology of Education, 75, 328-348. doi:10.2307/3090282

MacMillan, D., \& Reschly, D. (1998). Overrepresentation of minority students. The Journal of Special Education, 32, 15-24. doi:10.1177/002246699803200103

Mamlin, N., \& Harris, K. R. (1998). Elementary teachers' referral to special education in light of inclusion and prereferral: "Every child is here to learn . . . but some of these children are in real trouble." Journal of Educational Psychology, 90, 385396. doi:10.1037/0022-0663.90.3.385

Mccall, Z., \& Skrtic, T. (2009). Intersectional needs politics: A policy frame for the wicked problem of disproportionality. Multiple Voices for Ethnically Diverse Exceptional Learners, 11, 3-23.

McDonald, K. E., Keys, C. B., \& Balcazar, F. E. (2007). Disability, race/ethnicity and gender: Themes of cultural oppression, acts of individual resistance. American Journal of Community Psychology, 39, 145-161. doi:10.1007/s10464-007-9094-3

McGrath, D. J., \& Kuriloff, P. J. (1999). "They're going to tear the doors off this place": Upper-middle-class parent school involvement and the educational opportunities of other people's children. Educational Policy, 13, 603-629. doi:10.1177/ 0895904899013005001 
McKown, C., \& Weinstein, R. S. (2002). Modeling the role of child ethnicity and gender in children's deifferential response to teacher expectations. Journal of Applied Social Psychology, 32, 159-184. doi:10.1111/j.1559-1816.2002.tb01425.x

Mehan, H. 1941, Hertweck, A. 1937, \& Meihls, J. L. 1954. (1986). Handicapping the handicapped: Decision making in students' educational careers. Stanford, CA: Stanford University Press.

Mercer, J. (1973). Labeling the mentally retarded: Clinical and social system perspectives on mental retardation. Berkeley, CA: University of California Press.

Mickelson, R. A. (2001). Subverting Swann: First-and second-generation segregation in the Charlotte-Mecklenburg schools. American Educational Research Journal, 38, 215-252. doi:10.3102/00028312038002215

Mickelson, R. A., Bottia, M. C., \& Lambert, R. (2013). Effects of school racial composition on K-12 mathematics outcomes: A metaregression analysis. Review of Educational Research, 83, 121-158. doi:10.3102/0034654312475322

Morgan, P. L., Farkas, G., Cook, M., Strassfeld, N. M., Hillemeier, M. M., Pun, W. H., \& Schussler, D. L. (2016). Are Black children disproportionately overrepresented in special education? A best-evidence synthesis. Exceptional Children, 83, 181-198. doi:10.1177/0014402916664042

Morgan, P. L., Farkas, G., Hillemeier, M. M., Mattison, R., Maczuga, S., Li, H., \& Cook, M. (2015). Minorities are disproportionately underrepresented in special education: Longitudinal evidence across five disability conditions. Educational Researcher, 44, 278-292. doi:10.3102/0013189X15591157

Morgan, P. L., Frisco, M., Farkas, G., \& Hibel, J. (2010). A propensity score matching analysis of the effects of special education services. The Journal of Special Education, 43, 236-254. doi:10.1177/0022466908323007

National Center for Education Statistics. (2017). Children 3 to 21 years old served under Individuals with Disabilities Education Act (IDEA), Part B, by type of disability: Selected years, 1976-77 through 2015-16. Retrieved from https://nces .ed.gov/programs/digest/d17/tables/dt17_204.30.asp

Noguera, P. A. (2001). Racial politics and the elusive quest for excellence and equity in education. Education and Urban Society, 34, 18-41. doi:10.1177/0013124 501341003

Oakes, J. (1985). Keeping track: How schools structure inequality. New Haven, CT: Yale University Press.

Ong-Dean, C. (2006). High roads and low roads: Learning disabilities in California, 1976-1998. Sociological Perspectives, 49, 91-113. doi:10.1525/sop.2006.49.1.91

Ong-Dean, C. (2009). Distinguishing disability: Parents, privilege, and special education. Chicago, IL: University of Chicago Press.

Oswald, D., Coutinho, M., Best, A., \& Nguyen, N. (2001). Impact of sociodemographic characteristics on the identification rates of minority students as having mental retardation. Mental Retardation, 39, 351-367. doi:10.1352/00476765(2001)039<0351:IOSCOT>2.0.CO;2

Pigott, R. L., \& Cowen, E. L. (2000). Teacher race, child race, racial congruence, and teacher ratings of children's school adjustment. Journal of School Psychology, 38, 177-195. doi:10.1016/S0022-4405(99)00041-2

Reid, D. K., \& Knight, M. G. (2006). Disability justifies exclusion of minority students: A critical history grounded in disability studies. Educational Researcher, 35(6), 18-23. doi:10.3102/0013189X035006018

Reid, D. K., \& Valle, J. W. (2004). The discursive practice of learning disability: Implications for instruction and parent school relations. Journal of Learning Disabilities, 37, 466-481. doi:10.1177/00222194040370060101 
Rosenthal, R., \& Jacobson, L. (1968). Pygmalion in the classroom. The Urban Review, 3, 16-20.

Rutherford, R. B., Bullis, M., \& Anderson, C. W. (2002). Youth with disabilities in the correctional system: Prevalence rates and identification issues. Washington, DC: Office of Juvenile Justice and Delinquency Prevention.

Sax, L. (2003). Who first suggests the diagnosis of attention-deficit/hyperactivity disorder? The Annals of Family Medicine, 1, 171-174. doi:10.1370/afm.3

Shifrer, D. (2018). Clarifying the social roots of the disproportionate classification of racial minorities and males with learning disabilities. Sociological Quarterly, 59, 384-406. doi:10.1080/00380253.2018.1479198

Shifrer, D, Callahan, R. M., \& Muller, C. (2013). Equity or marginalization? American Educational Research Journal, 50, 656-682. doi:10.3102/0002831213479439

Shifrer, D., \& Fish, R. (2015, August). Differences across schools in otherwise similar students' likelibood of placement into special education. Paper presented at the American Sociological Association annual conference, Chicago, IL.

Shifrer, D., Muller, C., \& Callahan, R. (2011). Disproportionality and learning disabilities: Parsing apart race, socioeconomic status, and language. Journal of Learning Disabilities, 44, 246-257. doi:10.1177/0022219410374236

Skiba, R. J., Poloni-Staudinger, L., Simmons, A. B., Feggins-Azziz, L. R., \& ChoongGeun, C. (2005). Unproven links: Can poverty explain ethnic disproportionality in special education? 39, 130-44. doi:10.1177/00224669050390030101.

Sleeter, C. (1987). Why is there learning disabilities? A critical analysis of the birth of the field in its social context. In T. S. Popkewitz (Ed.), The formation of school subjects: The struggle for creating an American institution (pp. 210-237). London, England: Falmer Press.

Smith, D. D., \& Tyler, N. C. (2015). Introduction to contemporary special education. London, England: Pearson.

Special Education Longitudinal Study. (2005). Declassification-students who leave special education: A special topic report from the special education elementary longitudinal study. Menlo Park, CA: SRI International.

Staiger, A. (2004). Whiteness as giftedness: Racial formation at an urban high school. Social Problems, 51, 161-181. doi:10.1525/sp.2004.51.2.161

StataCorp. (2013). Stata [Computer software] (13th ed.). College Station, TX: Author.

Sullivan, A. L., \& Bal, A. (2013). Disproportionality in special education: Effects of individual and school variables on disability risk. Exceptional Children, 79, 475-494. doi:10.1177/001440291307900406

Thomas, A. (2000). Stability of Tringo's hierarchy of preference toward disability groups: 30 years later. Psychological Reports, 86, 1155-1156. doi:10.2466/ pr0.2000.86.3c. 1155

Tringo, J. L. (1970). The hierarchy of preference toward disability groups. The Journal of Special Education, 4, 295-306. doi:10.1177/002246697000400306

Tyson, K. (2011). Integration interrupted. In Tracking, Black students, and acting White after Brown. Oxford, England: Oxford University Press.

Tyson, K., Darity, W., Jr., \& Castellino, D. R. (2005). It's not "a Black thing": Understanding the burden of acting White and other dilemmas of high achievement. American Sociological Review, 70, 582-605. doi:10.1177/000312240 507000403

U.S. Department of Education, \& Office of Special Education and Rehabilitative Services. (2010). Thirty-five years of progress in educating children with disabilities through IDEA. Washington, DC: Author.

U.S. Department of Education, Office of Special Education and Rehabilitative Services, \& Office of Special Education Programs. (2015). 37th Annual report 
to congress on the implementation of the individuals with disabilities education Act 2015. Washington, DC: Author.

U.S. Department of Education, Office of Special Education and Rehabilitative Services, \& Office of Special Education Programs. (2016, December 12). Fact sheet: Equity in IDEA. Washington, DC: Author. Retrieved from https:// www.ed.gov/news/press-releases/fact-sheet-equity-idea

Vanneman, A., Hamilton, L., Anderson, J. B., \& Rahman, T. (2009). Achievement gaps: How Black and White students in public schools perform in mathematics and reading on the National Assessment of Educational Progress. Washington, DC: U.S. Department of Education. Retrieved from https://files.eric.ed.gov/fulltext/ ED505903.pdf

Voulgarides, C. K. (2018, March 20). Why DeVos's plan to delay Obama-era rule on minority special-education students is a mistake. Washington Post. Retrieved from https://www.washingtonpost.com/news/answer-sheet/wp/2018/03/20/ why-devoss-plan-to-delay-obama-era-rule-on-minority-special-education-stud ents-is-a-mistake/?utm_term $=.05$ d66a3a44f1

Wells, A. S., \& Serna, I. (1996). The politics of culture: Understanding local political resistance to detracking in racially mixed schools Harvard Educational Review, 66, 93-119. doi:10.17763/haer.66.1.274848214743t373

Wisconsin Department of Public Instruction. (n.d.). Federal definition/criteria for specific learning disabilities. Retrieved from https://dpi.wi.gov/sped/program/ specific-learning-disabilities/criteria/federal-definition-criteria

Manuscript received April 5, 2018 Final revision received April 4, 2019

Accepted April 11, 2019 